\title{
THE CURRENT STATE OF RESEARCH ON ACADEMIC DISHONESTY AMONG ENGINEERING STUDENTS
}

\author{
Trevor S. Harding ${ }^{1}$, Donald D. Carpenter ${ }^{2}$, Susan M. Montgomery ${ }^{3}$, Nicholas H. Steneck ${ }^{4}$
}

\begin{abstract}
Academic dishonesty, or cheating, has become a serious problem at colleges and universities. This is particularly true of engineering students who, are among the most likely to cheat in college. The present paper will review the literature as a basis of broadly understanding academic dishonesty. This discussion will focus on three primary issues: (1) perceptions of and attitudes towards cheating, (2) reasons for student cheating, and (3) methods of promoting academic integrity. A current research project being developed by the authors will also be discussed. The premise of this research is that students are constantly making ethical judgements between the pressure to cheat and their own moral beliefs and social norms. The goal then is to uncover the reasons for and frequency of student cheating and to develop best practices for helping engineering students avoid this pressure. Particular topics of discussion will include a rationale for the research methodology, an outline of the questions we hope the survey will answer and a discussion of the ethical implications of conducting research of this type. The authors hope to present preliminary results of this study during the presentation of the paper.
\end{abstract}

Index Terms - Academic dishonesty, cheating, educational research, honor codes

\section{INTRODUCTION}

Cheating appears to have become a serious problem at institutions of higher learning. In a 1999 meta-analysis on academic dishonesty research, McCabe and Drinan found widespread cheating on academic campuses across the country [1]. In one study as many as $75 \%$ of students admitted to one or more instances of serious cheating on a test or examination, up from $39 \%$ on the same campuses in 1963 [2]. Maramark and Maline came to a similar conclusion in their own analysis of studies conducted over the past 30 years [3].

Distressingly, engineering students appear to be among the most frequent cheaters. In one of the more recent studies conducted by Meade, roughly $74 \%$ of engineering students said they had engaged in some form of academic dishonesty while in college, compared to $87 \%$ of business students, $67 \%$ of science students and $63 \%$ of humanities students [4]. Despite these alarming rates, little attention has been given to the problem of cheating among engineering students in the educational research. For the most part, researchers have focused their attention on large, homogeneous samples of students that are representative of entire student populations rather than specific subsets of the population.

In this paper, we review the current literature on cheating, including a discussion of student's perceptions of and attitudes towards cheating, their reasons for cheating and methods of promoting academic integrity. This review provides the backdrop for a broad study of cheating among engineering and pre-engineering students at a variety of institutions that we are presently completing. We hope to present preliminary results of this study during the presentation of this paper. The second part of this paper describes our study, including our rationale for the methodology chosen, the questions we hope to answer and the ethical issues taken into consideration when conducting this research.

\section{EDUCATIONAL RESEARCH ON CHEATING}

Social scientists have studied many aspects of academic dishonesty among undergraduate students. Although some of their research has been focused on specific student populations, notably business and economics, little has been directed at the field of engineering. In designing our study, we have been guided by findings from other areas, but understand that engineering may have some unique characteristics. The following is a summary of the literature as it currently stands on cheating among undergraduate students including a discussion of student perceptions of and attitudes toward cheating, reasons for cheating and methods of promoting academic integrity.

\section{Perceptions of and Attitudes toward Cheating}

The overall perception among researchers is that cheating at academic institutions has become a problem of almost chronic levels. Perhaps not suprisingly, the majority of students $(85 \%)$ feel that cheating is a normal part of life [5].

\footnotetext{
${ }^{1}$ Trevor S. Harding, Kettering University, Industrial and Manufacturing Engineering and Business, Flint, MI 48504 tharding @kettering.edu

${ }^{2}$ Donald D. Carpenter, University of Michigan, Civil and Environmental Engineering, Ann Arbor, MI 48109 dcarpent @engin.umich.edu

${ }^{3}$ Susan M. Montgomery, University of Michigan, Chemical Engineering, Ann Arbor, MI 48109 smontgom@engin.umich.edu

${ }^{4}$ Nicholas H. Steneck, University of Michigan, Department of History, Ann Arbor, MI 48109 nsteneck@umich.edu
} 
This tends to be a widely held belief, despite differences in age, background and academic ability. Interestingly, students often believe that their peers are cheating at a level in excess of their own. In a study conducted by the authors, $95 \%$ of the students surveyed indicated that they believed that other students cheated more frequently than they did [6]. The result is that students create a self-fulfilling prophecy in which they justify cheating just to keep up with other students.

Since faculty will be involved in any effort to diminish cheating, it is also valuable to gauge their perceptions of cheating. It is well known that students and faculty differ widely on their beliefs about cheating $[7,8,9,10]$. In a study of 400 students and 120 professors at northeastern universities, Roig and Ballew found that students and faculty agree as to a professor's attitudes toward cheating [11]. However, professors thought that students would be more tolerant of cheating than students actually reported to be. Faculty also perceive that students cheat because of laziness or from a lack of understanding of the material [29], which may not be the case.

Using the moral indignation of peer students as a way to curtail cheating has been postulated. Whitley and Kost found that students tend to be more accepting of cheaters that they consider to be their friends, that they identify as having a "need" to cheat, or if they thought they could find themselves in the same situation [12]. In addition, they found that students felt cheating was warranted if the task was too difficult. Students identified these factors as social norms and that they were more likely to cheat if they believed that the social norm supports their behavior.

\section{Reasons for Student Cheating}

Researchers have generally divided reasons for cheating into three categories: demographic factors [13], psychological factors $[14,15,16]$ and situational or organizational factors $[10,17,18]$. Each of these is probably involved to one degree or another in a complex set that determines whether or not a particular student will cheat.

Psychological factors are reported by many researchers to be the single most important factor in student cheating. Roth and McCabe found a strong correlation between student values congruence (agreement between student and faculty values) and cheating, suggesting that student values are a stronger predictor of cheating than task reliability (the extent to which students and faculty viewed themselves and each other as unreliable) [7]. In 1964, Bowers found that $64 \%$ of students who cheated in high school also cheated in college, and that $67 \%$ of those that did not cheat in high school did not cheat in college [28]. Despite the age of this data it points to the importance of student values.

Another example that suggests the significance of student values is the success of honor codes at colleges and universities in reducing cheating. Carefully designed honor codes, which speak directly to student moral and ethical standards, have been found to reduce the levels of repetitive cheating [1,7].

Demographic factors do not in general appear to play as significant a role in determining whether a student can be expected to cheat. Several investigators have found little, if any, correlation between ethnicity and cheating $[19,20]$ and the influence of gender appears to be mixed. Women report cheating at significantly lower levels than male students [7], though some studies have found very weak correlation between gender and levels of cheating [21]. Similarly, only mixed correlates have been identified between student gender and perceptions of deating. Women often view cheating more negatively than men, which has been related to their moral self that is generally associated with social networks and burdened by responsibilities rather than rights and rightful claims, as is the case with men [21].

Other demographic factors of interest have included grades, age and religiosity. A moderate inverse correlation has been observed between cheating and grades or GPA $[22,23,24]$. Students appear to cheat more frequently as they matriculate from freshmen to seniors 25]; however, older non-traditional students cheat less often than their younger peers $[22,26]$. No correlation has been found between cheating and religious beliefs [27].

Subcultures, such as fraternities, sororities and athletic teams, also influence attitudes toward cheating. Several researchers have found that students involved in these organizations are more likely to cheat than their peers $[2,22,25,28]$.

Finally, several investigators have examined the relationship between situational factors and academic dishonesty. The majority of these findings are based on student opinion and little research has been done to determine whether they have any real effect. The most common situational factor is the pressure to succeed in school, but may also include high family expectations, importance of good grades for future advancement, external work commitments and heavy course loads [1,4,29].

Some students also place the blame for cheating on faculty for irrelevant course material, poor instructional quality and a lack of connection between assignments and course material 28]. In addition, the academic climate of the institution that a student attends may be an important situational factor. Some researchers believe that the climate at most institutions has eroded to the point that cheaters face trivial penalties, if any, and faculty members pay so little attention to academic dishonesty that students conclude it is foolish not to cheat [1].

\section{Promoting Academic Integrity}

Given the alarming state of academic dishonesty among our nation's institutions of higher learning, understanding what factors may reduce student cheating seems appropriate. Arguably, the responsibility for reducing cheating lies with both students and academic institutions, but the greatest 
reduction in cheating may come from faculty who insist on the highest levels of integrity in their classrooms.

Donald McCabe and Gary Pavela have identified Ten Principles of Academic Integrity for Faculty [30]. These principles can help to guide us in developing approaches for discouraging academic dishonesty within our classrooms and throughout our institutions. These principles are listed here for the reader's convenience:

- Affirm the importance of academic integrity

- Foster a love of learning

- Treat students as ends in themselves

- Foster an environment of trust in the classroom

- Encourage student responsibility for academic integrity

- Clarify expectations for students

- Develop fair and relevant forms of assessment

- Reduce opportunities to engage in academic dishonesty

- Challenge academic dishonesty when it occurs

- Help define and support campus-wide academic integrity standards

One of the most important aspects of reducing cheating is to ensure that faculty and students understand the values and expectations of the institution. The institution's policy of academic integrity must reflect these values and be actively promoted by the administration [29]. Simply discussing the institution's policy and the penalties associated with cheating has been shown to be ineffective [7,31]. A preferable approach is to increase the understanding of what constitutes cheating and the communication about academic integrity between students and faculty.

The institutional response to cheating is often to develop an academic dishonesty policy. Academic dishonesty policies can be effective if properly designed. Schools with well designed, and communicated, honor codes are known to have lower rates of cheating [1,7]. As mentioned previously, this may be related to the strong correlation between student values and cheating. However, their greatest weakness seems to be that few faculty actually use them for dealing with cases of academic dishonesty, despite institutional requirements to do so. Instead, faculty often prefer to handle cases individually because it is either too difficult to prove, there is a lack of knowledge regarding the policies of the institution, or the institution has an organizational culture that discourages faculty from reporting such cases [32,33]. Unfortunately this approach leads to an inherently unfair situation in which similar cases are treated differently, punishments are not consistent and repeat offenders are not identified. Furthermore, faculty who use informal adjudication in resolving instances of cheating may be violating the students right to due process, and therefore, placing themselves in serious legal jeopardy.
While convincing faculty to use institutional dishonesty policies deserves considerable effort, it might be more beneficial to encourage faculty to create a classroom environment where academic integrity is seen as essential and cheating is prevented before it even occurs. The inherent benefit of this approach is that we produce students who have a strong ethical foundation, rather than a wellstocked toolbox of techniques for concealing their cheating.

Simply relying on students to reduce the level of cheating may not be a fruitful endeavor since research suggests that they are not likely to report the cheating of other students. Centra found that approximately $71 \%$ of students would do nothing or simply express concern to the student individually B4]. Only 5\% would actually report the incident to the instructor and name the student involved. Students realize how difficult it can be to maintain ones integrity in the face of the many pressures they experience while in school. Given this and the general socialization process they have undergone since elementary school of not tattling on one another, it is no wonder that students won't report instances of cheating.

\section{OVERVIEW OF PLANNED RESEARCH STUDY ON CHEATING AMONG ENGINEERING STUDENTS}

The authors of the present paper are currently involved in a research program to examine academic dishonesty, its roots and possible remedies, within the undergraduate engineering population in particular. The goal of this study is to examine why engineering students cheat at higher rates than other students do and to develop pedagogical methods for reducing cheating that can be used by faculty to prevent cheating prior to its occurrence. The research program will be conducted in three distinct phases. In the initial phase, a survey will be distributed to a total of 1000 engineering and pre-engineering students at a small private university, a large public university, and several community colleges to produce a demographically varied sample. A second survey will be produced that more narrowly focuses on particularly strong correlations found in the initial survey. This second survey will be distributed to an increased number of students attending a larger group of institutions. Perhaps simultaneously, faculty will be surveyed for comparison with the responses of their students, in terms of perceptions of cheating. Finally, focus groups of faculty and students will be formed in an effort to gain deeper insight into the issues involved than may be possible with a survey format.

The primary research tool is the direct question survey (DQS) approach, in which students are asked to anonymously respond to various questions regarding their own academic integrity and their perceptions of others' integrity. The advantages of this technique are the inherent anonymity and simplicity with which results can be obtained and analyzed from the completed surveys. Ensuring student anonymity on the survey is particularly important since it is 
thought to encourage more truthful responses [35]. The accuracy of this approach is somewhat uncertain. Research exists that suggests that the DQS method produces reasonably accurate estimates of the frequency of cheating [36]. However, other evidence suggests that this method leads to biased results [37,38]. Some researchers have found that the DQS technique leads to underestimates of the degree of cheating among students [37,38], while others have observed an overestimate [39].

A means of overcoming this bias is to use direct surreptitious observation (DSO) [40,41,42]. In this technique, students submit tests that are graded by the instructor (without marking on them) and the scores on each problem are recorded. The tests are then returned to the students for self-grading. Cheating is therefore indicated when the student's score differs significantly from the instructor's. While this technique may provide a more accurate measure of the frequency of cheating, it provides no information about why these students cheated. Furthermore, it is a method that may have serious ethical implications considering that student anonymity is not guaranteed and it places students in a contrived scenario. For these reasons we decided against this method.

\section{OUTLINE OF DATA TO BE COLlECTED}

From the initial study, data will be collected that we hope will address the following questions:

\section{What actions do students consider to be cheating?}

Many students and faculty differ as to their definition of what cheating encompasses. This part of the survey asks students to classify twenty behaviors, such as "taking an exam for another student," and "studying with other students for a test," as either cheating, unethical but not cheating, or neither. In addition, students are asked to indicate whether they have engaged in such behaviors, and if so, how many times. The goal here is to identify student perceptions of what is cheating for later comparison with faculty responses, and to generate a baseline for the rate at which students are cheating.

\section{How well are institutional academic dishonesty policies communicated, understood and enforced?}

One factor that has been examined in the research is the correlation between levels of cheating and how well an institutions honor code is communicated to faculty and students. In this section students are asked whether their institution's academic dishonesty policies are well understood, supported, and whether they deter cheating. These responses will be compared with those of faculty in a later phase of the research.

\section{What ethical considerations do students make when faced with the opportunity to cheat?}

Since values seem to be an important factor in determining whether students will cheat, we are interested in examining this effect in different situations. Students are presented with three scenarios in which they are asked to consider cheating on an exam, a homework assignment, and a written term paper. They are asked whether shame, embarrassment or the threat of formal sanctions would have any effect on their decision to cheat. From this data we hope to determine the relative importance of personal standards (shame), social norms (embarrassment), and institutional rules (formal sanctions).

\section{Under what circumstances do students consider cheating acceptable?}

To explore reasons that students might cheat, they are asked to reflect on whether it's OK to cheat under twelve circumstances. The majority of these circumstances focus on the influence of situational factors, such as whether the instructor left the room during the exam, or whether a student is in danger of failing the class.

\section{What is the responsibility of various parties in deterring cheating and what personal pressures lead to cheating?}

Students are asked to reflect on 17 statements, such as whether the responsibility to deter cheating lies with faculty, administration, or themselves; what action they would take if they saw a classmate cheat; and what pressures they feel to cheat, such as not wanting to let their family down and wanting to help a friend.

\section{What actions might prevent students from cheating?}

The overall purpose of the research is to identify methods of reducing the extent of cheating among engineering students. Therefore, students are presented with twenty-three actions and are asked to comment on whether such actions would prevent them from cheating.

\section{Is there any correlation between the responses above and demographic data?}

Students are asked to provide their age, gender, class level, school, GPA, background, other responsibilities, parents' education and economic background, their reasons for studying engineering, and how often they cheated in high school. 


\section{ETHICAL CONSIDERATIONS}

Since cheating violates the academic policies of the institutions we are studying, asking students to reveal whether they have cheated raises important ethical considerations. Among these are three areas of concern: respect for the rights and autonomy of our research subjects, issues raised by the way in which our data are presented, and possible infringements on scholarly independence.

We sought to protect the privacy of our research subjects in three ways: 1) anonymous surveys, 2) voluntary participation, and 3) presentation of data such that individual students can not be identified (discussed in more detail could still affect our research subjects in ways they had not anticipated, which is an infringement on their rights (to be informed in advance of all consequences) and autonomy (to be in control of events that could change their lives). For example, simply asking them to participate in a study on cheating could change their attitudes toward their instructors or institutions. "Why are we being asked to participate in this study?" "Doesn't our instructor or school trust us?" On balance, we feel that the benefits gained from raising these questions will outweigh the risks, but we must remain mindful of the fact that the research could affect our subjects in ways that either they or we did not anticipate.

The ethical issues raised by the way our data are presented are a generally recognized problem in all survey research. We would like to look at individual characteristics. Do factors such as race, gender, ethnicity, socioeconomic background, religion, prior educational experience, and so on predict high or low standards for academic integrity? Unfortunately, since elements of our survey populations are fairly small, we cannot explore some of these issues because we could have only one or two students falling into a particular category. Before publication, therefore, results will be reviewed to ensure that individuals are not identifiable.

Finally, with regards to possible infringements on scholarly independence, conflicts have arisen with institutional administrators, who have a responsibility to safeguard the reputations of their institutions. While this responsibility does not justify concealing widespread cheating on a campus if it existed, it could justify careful reporting of our results so that an institution is fairly represented, particularly in comparison to other institutions. While we are confident that the deeper understanding of cheating that our study will provide will in the long term benefit academic institutions, the fact remains that the raw figures on ates of cheating are potentially damaging to institutional reputations. Moreover, since we need institutional permission to carry out our survey, as researchers we could be constrained by institutional oversight requirements, such as possible pre-publication review, limitations on the way we presented our data, and so below). These protections notwithstanding, our survey

on. Fortunately, we were able to work through these issues without having to compromise the integrity of our study, but in undertaking work such as this, maintaining scholarly independence is not automatically assured.

\section{SUMMARY}

There is little doubt from the research that cheating in college is occurring at alarming rates, particularly among engineering students. Research on cheating began slowly, with the majority of the effort focusing on establishing the frequency with which cheating occurred. With time, more attention has been given to understanding the underlying causes of cheating. It would appear that student values are perhaps the most important factor in determining whether a student will cheat. The influence of other variables, such as demographic (gender, race, age, grades, etc.) and situational (poor teaching, lack of honor code, heavy course loads, etc.) factors, appears to be mixed at best.

The best approach to preventing cheating may be to appeal to students higher morals since values seem to be so important, rather than simply trying to catch cheaters. This requires the involvement of faculty who must insist on the highest levels of ethical behavior in their classes. Primarily, this has been the approach of schools with honor codes that have demonstrated a reduction in levels of cheating.

Within this framework of understanding, the authors have outlined a research study that will examine academic dishonesty among engineering students in an effort to develop techniques for reducing cheating. Using a survey format, the study asks students to report on their perceptions and attitudes toward cheating, why they might cheat and what factors might make cheating less likely. In this paper we have discussed the outline of this study, the questions we hope to answer and the ethical issues that were considered in developing this research program.

\section{REFERENCES}

1 McCabe, D. and Drinan, P., "Toward a Culture of Academic Integrity," Chronicle of Higher Education, 1999, 46(8).

2 Bowers, W.J., Student Dishonesty and Its Control in College, New York: Bureau of Applied Social Research, Columbia University, 1964.

3 Maramark, S. and Maline, M.B., Issues in Education: Academic dishonesty among college students, Washington, D.C.: U.S. Department of Education, Office of Educational Research and Improvement, 1993.

4 Meade, J., "Cheating: Is academic dishonesty par for the course?", ASEE Prism, March 1992, 30-32.

5 Baird, J.S., Jr., "Current Trends in College Cheating," Psychology in the Schools, 17(4), 1980, 515-522.

6 Harding, T.S., "On the Frequency and Causes of Academic Dishonesty Among Engineering Students," Proceedings 2001 American Society for Engineering Education, Washington, D.C.: ASEE, 2001.

7 Roth, N.L. and McCabe, D.L.," Communication Strategies for Addressing Academic Dishonesty,” Journal of College Student Development, 36(6), 1995, 531-541.

8 Sims, R.L., "The Severity of Academic Dishonesty: A comparison of faculty and student views," Psychology in the Schools, 32(3), 1993, 233238 .

\section{0-7803-6669-7/01/\$10.00 @ 2001 IEEE}

October 10 - 13, 2001 Reno, NV

$31^{\text {st }}$ ASEE/IEEE Frontiers in Education Conference 
9 Barnett, D.C. and Dalton, J.C., "Why College Students Cheat," Journal of College Student Personnel, 22, 1981, 545-551.

10 Stern, E.B. and Havlicek, L., "Academic Misconduct: Results of faculty and undergraduate student surveys," Journal of Allied Health, 15(2), 1986, 129-142.

11 Roig, M. and Ballew, C., "Attitudes Toward Cheating of Self and Others by College Students and Professors," The Psychological Record, 44, 1994, 3-12.

12 Whitley, Jr., B.E. and Kost, C.R., "College Students' Perceptions of Peers who Cheat." Journal of Applied Social Psychology, 29(8), 1999, 1732-1760.

13 Ward, D.A. and Beck, W.L., "Gender and Dishonesty," Journal of Social Psychology, 130, 1990, 333-339.

14 Haines, V.J., Diekhoff, G.M., LaBeff, E.E. and Clark, R., "College Cheating: Immaturity, Lack of Commitment, and the Neutralizing Attitude," Research in Higher Education, 25, 1986, 342-354.

15 LaBeff, E.E., Clark, R.E., Haines, V.J. and Diekhoff, G.M., "Situational Ethics and College Student Cheating," Sociological Inquiry, 60, 1990, 190-197.

16 Perry, A.R., Kane, K.M., Bernesser, K.J., and Spicker, P.T., “Type A Behavior, Competitive Achievement-striving, and Cheating Among College Students," Psychological Reports, 66, 1990, 459-465.

17 Nuss, E.M., "Academic Integrity: Comparing faculty and student attitudes," Improving College and University Teaching, 32, 1984, 140144.

18 McCabe, D.L. and Trevino, L.K., "Academic Dishonesty: Honor codes and other contextual influences," Journal of Higher Education, 64, 1993, 522-538.

19 Sutton, E.M. and Hubba, M.E., "Undergraduate Student Perceptions of Academic Dishonest as a Function of Ethnicity and Religious Participation," NASPA Journal, 33(1), 1995, 19-34.

20 Kuehn, P., Stanwyck, D.J. and Holland , C.L., "Attitudes Toward 'Cheating' Behaviors in the ESL Classroom," TESOL Quarterly, 24(2), 1990, 313-317.

21 Whitley, Jr., B.E., Bichlmeier, A. and Jones, C.J., "Gender Differences in Cheating Attitudes and Classroom Cheating Behavior: a meta analysis," Sex Roles, 41(9), 1999, 657-680.

22 Diekhoff, G.M., et al., "College Cheating: Ten years later," Research in Higher Education, 37(4), 1996, 487-502.

23 Graham, M.A., Monday, J., O'Brien, K. and Steffen, S., "Cheating at Small Colleges: An examination of student and faculty attitudes and behaviors," Journal of College Student Development, 35(4), 1994, 255 260.

24 Roig, M. and DeTommaso, L., "Are College Cheating and Plagiarism Related to Academic Dishonesty?" Psychological Reports, 77, 1995, 691-698.
25 Moffatt, M., Undergraduate Cheating, New Brunswick, NJ: Rutgers University Press, 1990.

26 Newstead, S.E., Franklyn-Stokes, A. and Armstead, P., "Individual Differences in Student Cheating," Journal of Educational Psychology, 88(2), 1996, 229-241.

27 Nowell, C. and Laufer, D., "Undergraduate Cheating in the Fields of Business and Economics," Journal of Economic Education, 28(1), 1997, 3-12.

28 McCabe, D., Trevino, L.K. and Butterfield, K.D., "Academic Integrity in Honor Code and Non-Honor Code Environments: A qualitative investigation," Journal of Higher Education, 70(2), 1999, 211-234

29 Hall, T. and Kuh, G.D., "Honor Among Students: Academic integrity and honor codes at state-assisted universities," NASPA Journal,36(1), 1998, 2-18.

30 McCabe, D. and Pavela, G., "Faculty and Academic Integrity", Synthesis: Law and Policy in Higher Education, (Summer), 1997.

31 Cochran, J.K., Chamlin, M.B., Wood, P.B. and Sellers, C.S., "Shame, Embarrassment, and Formal Sanction Threats: Extending the deterrence/rational choice model to academic dishonesty," Sociological Inquiry, 69(1), 1999, 91-105.

32 Schneider, A., "Why Professors Don't Do More to Stop Students Who Cheat," The Chronicle of Higher Education, January 22,1999.

33 Jendrek, M.P., "Faculty Reactions to Academic Dishonesty," Journal of College Student Development, 33(3), 1989, 260-273.

34 Centra, J.A., "College Freshmen Attitudes Toward Cheating," Personnel and Guidance Journal, 48(5), 1970, 366-373.

35 Chaudhuri, A. and Mukherjee, R., Randomized Response: Theory and techniques, New York: Marcel Dekker, 1988.

36 Erickson, M.L. and Smith, W.B., "On the Relationship between Selfreported and actual deviance: An empirical test.," Humboldt Journal of Social Relations, 1(2), 1974, 106-113.

37 Kerkvliet, J., "Cheating by Economics Students: A comparison of survey results," Journal of Economic Education, 25 (Spring), 1994, 121-133.

38 Scheers, N. and Dayton, M., "Improved Estimation of Academic Cheating Behavior Using the Randomized Response Technique," Research in Higher Education, 26(1), 1987, 61-69.

39 Neson, T. and Schaefer, N., "Cheating Among College Students Estimated with the Randomized Response Technique," College Student Journal, 20 (Fall), 1986, 321-325.

40 Tittle, C. and Rowe, A., "Fear and the Student Cheater," Change, 6(3), 1974, 47-48.

41 Gardner, W., Roper, J., Gonzales, C., and Simpson, R., "Analysis of Cheating on Academic Assignments," Psychological Record, 38(4), 1988, 544-555.

42 Nowell, D. and Laufer, D., "Undergraduate Cheating in the Fields of Business and Economics," Journal of Economic Education, 28 (Winter), 1997, 3-12. 